\title{
Wall motion recovery in dobutamine stress magnetic resonance imaging
}

\author{
Alexander Berger", Sebastian U Kelle, Christopher Schneeweis, Michael Frick, Christoph Klein, Eckart Fleck, \\ Rolf Gebker
}

From 2011 SCMR/Euro CMR Joint Scientific Sessions

Nice, France. 3-6 February 2011

\section{Objectives}

To correlate the persistence of new or worsening induced wall motion abnormalities in dobutamine stress magnetic resonance imaging (DSMR) and the extent of coronary artery disease (CAD) in invasive coronary angiography.

\section{Background}

DSMR is a highly sensitive and specific non-invasive method for detecting induced wall motion abnormalities (IWMAs) in patients with significant CAD. Yet little is known about the duration of IWMA during the recovery period. We hypothesize that the persistence of IWMAs during recovery may be associated with the extent of CAD.

\section{Methods}

DSMR was performed in twenty-eight consecutive patients with suspected or known CAD scheduled for clinically indicated invasive coronary angiography. Each patient underwent routine DSMR including cine imaging at rest and during dobutamine infusion. Additionally, three standard short axis and longitudinal axis views were obtained after five, ten and fifteen minutes during the recovery period in order to detect persisting wall motion abnormalities in ischemic myocardial territories, which were assigned to coronary arteries based on the 17 segment model. Intermediate and severe coronary stenosis were defined as $50-75 \%$ and $>75 \%$ luminal narrowing using invasive coronary angiography, respectively (figure 1). All patients received esmolol

German Heart Institute Berlin, Berlin, Germany after stopping the dobutamine infusion to achieve a heart rate under 100bpm.

\section{Results}

The recovery time was associated with more severe CAD. Our data showed that the higher the wall motion score index was at peak stress, the longer IWMAs persisted during the recovery phase $(\mathrm{p}<0.01$, see figure 2$)$.

The wall motion score index showed significant differences in territories supplied by arteries with intermediate stenoses compared with severe stenoses under maximum stress (difference wall motion score index $\Delta$ WMSI $0.19 \pm 0.27$ vs. $0.37 \pm 0.32, \mathrm{p}=0.03$ ) and at five ( $\Delta$ WMSI $0.05 \pm 0.11$ vs. $0.22 \pm 0.26, \mathrm{p}=0.007$ ) and ten minutes ( $\Delta$ WMSI $0.01 \pm 0.04$ vs. $0.12 \pm 0.15, \mathrm{p}=0.005)$ during recovery phase.

Patients with intermediate and those with severe stenoses demonstrated no significant difference in the rate pressure product at maximum stress level $(\mathrm{p}=0,5)$, during recovery after five minutes $(\mathrm{p}=0.38)$ and ten minutes $(\mathrm{p}=0.16)$.

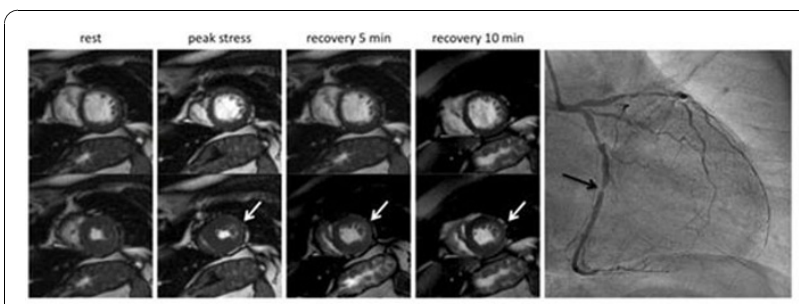

Figure 1 Left side: Short axis views during diastole (top row) and systole (bottom row) showing wall motion at rest, at peak stress level, after five minutes recovery and 10 minutes recovery. The white arrows mark the induced wall motion stress abnormality which sustains over the recovery period of ten minutes. Right side: Coronary angiography of the same patient showing a high grade stenosis of the mid RCX (black arrow).

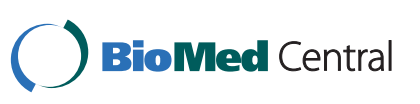

(c) 2011 Berger et al; licensee BioMed Central Ltd. This is an open access article distributed under the terms of the Creative Commons Attribution License (http://creativecommons.org/licenses/by/2.0), which permits unrestricted use, distribution, and reproduction in any medium, provided the original work is properly cited. 


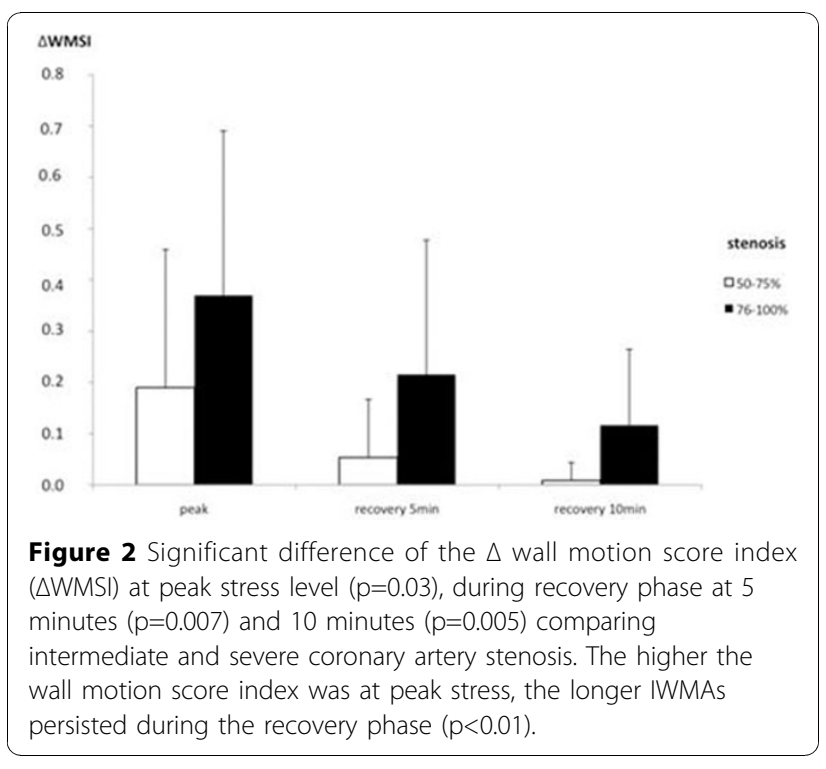

\section{Conclusions}

We demonstrated that normalization of left ventricular IWMAs is related to the extent of CAD. Cine imaging during the recovery phase may be helpful for additional risk stratification.

Published: 2 February 2011

Cite this article as: Berger et al:: Wall motion recovery in dobutamine

stress magnetic resonance imaging. Journal of Cardiovascular Magnetic Resonance 2011 13(Suppl 1):P99.

Submit your next manuscript to BioMed Central and take full advantage of:

- Convenient online submission

- Thorough peer review

- No space constraints or color figure charges

- Immediate publication on acceptance

- Inclusion in PubMed, CAS, Scopus and Google Scholar

- Research which is freely available for redistribution

Submit your manuscript at www.biomedcentral.com/submit
C Biomed Central 